\title{
Measuring procalcitonin (PCT) levels: a pilot study in early diagnosis of patients affected by ureterocutaneostomy infection
}

\author{
Dante Di Domenico, Manuela Pane, Raffaele Vitale, Michele Barbieri and Domenico Prezioso* \\ Department of Neuroscience, Reproductive Sciences and Dentistry, school of Urology, University Federico II of Naples, Italy
}

\section{Introduction}

Radical cystectomy is the conventional treatment when bladder cancer has spread through the muscle layer. There are several methods of post-operative urinary diversion that can be divided into two major categories: controllable and non-controllable by the patient. The skin ureterostomy (UCS) is an example of urinary diversion that cannot be controlled, mainly applicable to older patients with poor physical condition. many basic comorbidities, advanced cancer and for patients who cannot tolerate surgery long-term given the high anesthetic risk [1].

Urinary infections represent one of the major complications in patients affected by UCS, crucially determining a decreasing of renal functionality over time [2]. An early diagnosis is fundamental to improve the prognosis and block the progression, hence, allowing for therapy $[3,4]$.

Urine culture test currently represents the state of the art gold standard procedure for infection detection. However, a therapeutic protocol has to be established before the culture test results are available. Criteria such as, clinical judgment, the number of white blood cells (WBC) and the culture urinalysis (UA) are typically used to suggest the treatment to follow $[5,6]$. However, in clinical practice, symptoms cannot be often correlate with the severity of the disease and the WBC count is a non-specific indicator, thus, cannot differentiate the bacterial infection from the viral one or any other inflammatory conditions. Furthermore, a sample of contaminated urine may make difficult the interpretation of a UA.

The PCT is a precursor peptide of calcitonin, a hormone involved in calcium homeostasis and produced by proteolysis of preprocalcitonin. The level of PCT in the blood is usually less than $0.05 \mathrm{ng}$ / ml. Procalcitonin (PCT), is an effective marker for bacterial etiology infections and severity of the infection [7].

As a result of the bacterial infection arising and to a lesser extent fungal infection, PCT blood levels can reach higher concentrations, and its levels remain high until the infection has resolved [8].

The PCT has been studied in intensive care units where it can serve as a guide to determine when to start antibiotic therapy, its effectiveness, and when raising the dosage or switch to other antibiotics $[9,10]$. The PCT was also studied in various urological disorders. Compared with other biomarkers, PCT results dominant in predicting the severity of acute pyelonephritis [11] and studies reveals a correlation in predicting urinate positive cultures in patients with ureteral obstruction from calculations [12]. The overall goal of this study, has been instead, to determine whether a biomarker PCT is relevant and useful in daily practice to predict urinary tract infections in patients with UCS.

\section{Materials and methods}

The pilot study was performed at the A.O.U. Federico II of Naples observing data collected from June 2016 to January 2017 in patients who previously had undergone surgery for radical cystectomy and derivation with bilateral and unilateral UCS. Included criteria: age $>$ 18 years, an advanced bladder cancer diagnosis treated with radical cystectomy and UCS. Excluded criteria: patients under hemodialysis or peritoneal dialysis treatment, a history of renal transplantation, immunodeficiency, HIV or other conditions of immunosuppression.

Patients who met the inclusion criteria, data were observed as follow: PCT, leukocyte count with relative concentration percentage of neutrophils, and finally urine culture. Moreover, the patient's demographics and medical history data has been collected.

For each variable has been established a treshold to set as critical point and used to create a binomial distribution. For the WBC count limit was $>10 \mathrm{~K} / \mathrm{ml}$, for the PCT $>0.1 \mathrm{ng} / \mathrm{ml}$, for neutrophils $>70 \%$. Data have been analyzed with the SPSS statistical software to analyze these data [11].

Furthermore, has been possible to determine the area under the curve (ROC) from the threshold values, whereas from the data evidence has been defined the concept of PCT sensitivity against the value represented by positive UA.

\section{Results}

For all the duration of the study, 28 patients fit into the inclusion criteria. A porcentage of $32.2 \%$ patients were women, $68.8 \%$ were men with an average age of 71.2 years (range 59-86) (Table 1).

In total, 20/28 patients had positive UA ( $>10 \mathrm{~K}$ bacteria) (Table 2). The values for PCT, WBC count, Neutrophils\%, were compared for both culture-positive and negative. A ROC has been calculated for some markers using as a standard the AU (Figure 1). PCT has been the co-infected predictor in this cohort (AUC 0.713) (Table 3).

Correspondence to: Domenico Prezioso, Department of Neuroscience, Reproductive Sciences and Dentistry, school of Urology, University Federico II of Naples, Italy, Tel: 0817462606; E-mail: dantedid@gmail.com

Received: September 20, 2017; Accepted: October 09, 2017; Published: October 12,2017 


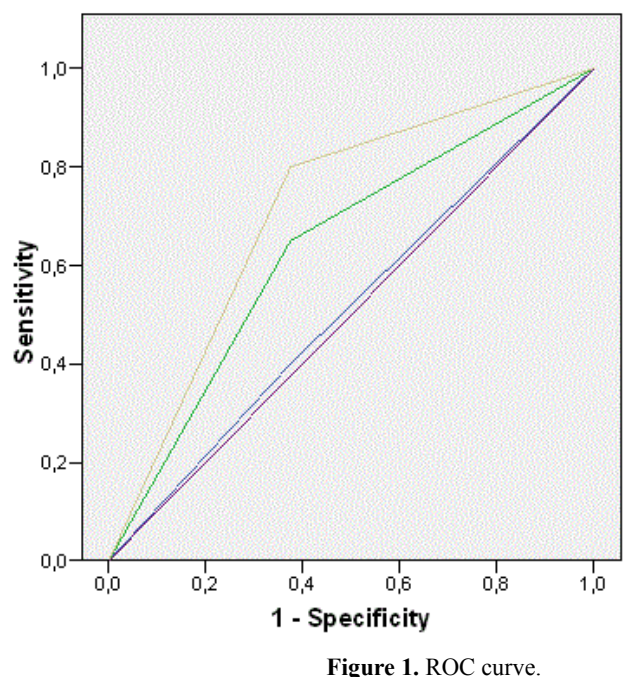

Source of the Curve - MEC(mm3) - Neutrofili $(\%)$ - Procalcitonina - Referenœ Line

Figure 1. ROC curve.

Table 1. Percntage of patients.

\begin{tabular}{|c|c|}
\hline Variables & $\boldsymbol{\#} \mathbf{}$ \\
\hline Average years (age) & $71.2(59-86)$ mean \\
\hline Male & 68.8 \\
\hline Female & 32.2 \\
\hline Diabetes mellitus & 28.5 \\
\hline Hypertension & 14.4 \\
\hline
\end{tabular}

Table 2. Case Processing Summary.

\begin{tabular}{|c|c|}
\hline Urinocoltura & Valid N (listwise) \\
\hline Positive(a) & 20 \\
\hline Negative & 8 \\
\hline
\end{tabular}

Table 3. Area Under the Curve.

\begin{tabular}{|c|c|}
\hline Test Result Variable(s) & Area \\
\hline WBC(mm3) & 0.513 \\
\hline Neutrofili (\%) & 0.638 \\
\hline Procalcitonina & 0.713 \\
\hline
\end{tabular}

\section{Discussion}

The presence and the severity of an infection associated with patients carrying UCS can be difficult to diagnose. The urine cultures still remain the gold standard for the confirmation of infection, although to a result is obtained in a time frame of 24-48 hours, and often a clinical decision must be taken in advance [3]. The PCT, precursor peptide of calcitonin, instead, is a marker for bacterial etiology infections and severity of the infection, simple and fast to be measured [7]. As a result of the bacterial infection, PCT blood levels can reach higher concentrations, and its levels remain high until the infection has resolved [8].

The PCT was also studied in various urological disorders (PCT results dominant in predicting the severity of acute pyelonephritis [11] and studies reveals a correlation in predicting urinate positive cultures in patients with ureteral obstruction from stones).

This pilot study has been initiated to determine if PCT is useful to predict positive UA in patients with UCS. The PCT has been found as a statistically meaningful marker as shown by AUC of 0.713 .

We believe that the results of this study, suggest PCT to be diagnostic tool in precise cases of clinical practice. Further studies could help in the future to verify the PCT ability to predict the infection against the white blood cell counts and other parameters. Additionally, there is no unanimity on the threshold for a positive procalcitonin test, and has been fixed the reference range of our institute, with a cut-off of $0.1 \mathrm{ng} / \mathrm{ml}$.

\section{Conclusions}

Among the markers of infection in patients with UCS, PCT may help urologists make a early detection of infection, differentiate sepsis from causes of severe systemic inflammation, and assess the severity. The pilot study shows that PCT exceeds the number of white blood cells, and the\% of neutrophils, in predicting urinary infections in patients with UCS.

\section{References}

1. Stenzl A, Cowan NC, De Santis M, Kuczyk MA, Merseburger AS, et al, (2011) Treatment of Muscle-invasive and Metastatic Bladder Cancer: Update of the EAU Guidelines. Eur Urol 59: 1009-1018.

2. C. De Nunzio, L. Cindolo, C. Leonardo, A. Antonelli, C. Ceruti, et al. (2013) Analysis of radical cystectomy and urinary diversion complications with the Clavien classification system in an Italian real-life cohort. Eur J Surg Oncol 39: 792-798

3. Angus DC, Linde-Zwirble WT, Lidicker J, Clermont G, Carcillo J, et al. (2001) Epidemiology of severe sepsis in the United States: analysis of incidence, outcome, and associated costs of care. Crit Care Med 29: 1303-1310. [Crossref]

4. Rivers E, Nguyen B, Havstad S, Ressler J, Muzzin A, et al. (2001) Early goal-directed therapy in the treatment of severe sepsis and septic shock. N Engl J Med 345: 13681377. [Crossref]

5. Gary T Kinasewitz, S Betty Yan, Bruce Basson, Philip Comp, James A Russell, et al (2004) Universal changes in biomarkers of coagulation and inflammation occur in patients with severe sepsis, regardless of causative micro-organism. J Crit Care 8: R82-90.

6. Tschaikowsky K, Hedwig-Geissing M, Braun GG, Radespiel-Troeger M (2011) Predictive value of procalcitonin, interleukin-6, and C-reactive protein for survival in postoperative patients with severe sepsis. J Crit Care 26: 54-64.

7. Cabral L, Afreixo V, Almeida L, Paiva JA (2016) The Use of Procalcitonin (PCT) for Diagnosis of Sepsis in Burn Patients: A Meta-Analysis. PLoS One 11: e0168475. [Crossref]

8. Lee H (2013) Procalcitonin as a biomarker of infectious diseases. Korean J Intern Med 28: 285-291. [Crossref]

9. Limper M, de Kruif MD, Duits AJ, Brandjes DP, van Gorp EC, et al. (2010) The diagnostic role of procalcitonin and other biomarkers in discriminating infectious from non-infectious fever. $J$ Infect 60: 409-416.

10. Schuetz P, Albrich W, Mueller B (2011) Procalcitonin for diagnosis of infection and guide to antibiotic decisions: past, present and future. BMC Med 9: 107. [Crossref]

11. Hausfater $P$, et al. Usefulness of procalcitonin as a marker of systemic infection in emergency department patients: A prospective study. Clin Infect Dis 34: 895-901.

12. Papagiannopoulos D, Whelan P, Ahmad W, Rybak J, Hota B, et al. (2016) Procalcitonin is a strong predictor of urine culture results in patients with obstructing ureteral stones: A prospective, pilot study Urol Ann 8: 277-280.

Copyright: (C2017 Domenico D. This is an open-access article distributed under the terms of the Creative Commons Attribution License, which permits unrestricted use, distribution, and reproduction in any medium, provided the original author and source are credited. 